\title{
Climate Change Risk Management and Coping Strategies for Sustainable Camel Production in the Case of Somali Region, Ethiopia
}

\author{
Fano Dargo Girmay* \\ Department of Dry-land Crop Science, Jigjiga University, Jigjiga, Ethiopia
}

Gebremedhin Gebreselassie

Department of Animal and Rage land Science, Jigjiga University, Jigjiga, Ethiopia

Aklilu Bajigo

Department of Natural Resource Management, Jigjiga University, Jigjiga, Ethiopia

\begin{abstract}
Climate changes are threatening the production of a camel in the Ethiopian Somali region. Its risk management and suitable coping strategies are not yet studied in the study area. Therefore, the current study is very crucial to assess the climate change risks management and coping strategies for sustainable camel production. Primary and secondary data were collected. During this study, 20 households were purposively selected from each kebelles. Simple Descriptive statistics were used to analyze the data. $19.6 \%$ of the respondents suggested that the impact of climate were Camel disease incidence, Feed shortage, and Water shortage equally. Furthermore, the study showedn that climate change impacts negatively on camel production and thus camel owners need to use risk management and coping strategies. $24.8 \%$ usedwere use Temporary camel relocation to other zones. While, Restocking, Planting drought tolerant browses trees and Conservingconserving rain water were the next strategies respectively. Awareness creation among pastoralists and agropastoral regarding on the dangers of climate change, and risk management and coping strategies for sustainable camel production, vigorous dissemination of the technologies/ / information and follow-up to ensure utilization and/or application are strongly recommended. Beside,Besides, Government should also assist camel farmers with reliable water sources such as canals and dams.
\end{abstract}

Keywords: Camel production; Climate change; Sustainable production; Risk management; Coping strategies.

(c) (f) CC BY: Creative Commons Attribution License 4.0

\section{Introduction}

Climate change in agriculture could be devastating in many areas. Many regions already feel these impacts, which will get progressively more severe as mean temperatures rise and the climate becomes more variable [1]. Scientific evidence about the seriousness of the climate threat to agriculture is now unambiguous, but the exact magnitude is uncertain because of the complex interactions and feedback processes in the ecosystem and the economy. Five main factors will affect agricultural productivity: changes in temperature, precipitation, carbon dioxide (CO2) fertilization, climate variability, and surface water runoff. Initially, rising atmospheric concentrations of carbon benefit crop growth and could offset yield losses from heat and water stress [2].

Climate change will have significant impacts on development, poverty alleviation, and the achievement of the Millennium Development Goals (MDGs). Hard-fought progress made in achieving these global goals may be slowed or even reversed by climate change as new threats emerge to water and food security, agricultural production, nutrition, and public health. Countries and regions that fail to adapt will contribute to global insecurity through the spread of disease, conflicts over resources, and a degradation of the economic system $[1,3]$.

According to the Intergovernmental Panel on Climate Change IPCC [2], climate change is real and becoming worse and most vulnerable people will be affected. The International Fund for Agricultural Development (IFAD) acknowledges climate change as one of the factors affecting rural poverty and challenged to address. While climate change is a global phenomenon, its negative impacts are more severely felt by poor people in developing countries who rely heavily on the natural resource base for their livelihoods $[1,4]$.

Agriculture and livestock keeping are amongst the climate-sensitive sectors. Presence of adverse climate change is supposed to be one of the major constraints on livestock production in the tropics. The seasonal pattern of rainfall results in large fluctuations in availability and quality of pasture over the year with high temperatures, high humidity, and intense solar radiation, lead to heat stress and discomfort $[1,5]$.

By 2020, in some African countries agricultural yields could be reduced by as much as 50\%; and by the 2080s, the area of arid and semi-arid land in Africa will likely increase by $5-8 \%$ [6].

Build expected climate change related trends into today's risk and vulnerability assessment based on current climate variability to craft effective short-, medium-, and long-term strategies strengthen the response capacities and preparedness, reduce risks, and promote effective adaptation. Current climate variability and dealing with ongoing disaster impacts is always going to be an essential focus for highly vulnerable communities. However, wherever possible these immediate concerns need to be integrated into longer term strategies that address future risk and the 
drivers of vulnerability. This can be done through development actions aimed at reducing overall vulnerabilities through addressing, for example, livelihoods, environmental degradation $[1,7,8]$.

Now a day's climate change is becoming a big concern in the world in general and the developing countries in particular. The anticipated climate change impacts including sea-level rise, increased temperatures, decreased water supplies, increased endemic diseases and deterioration in coastal conditions threaten island populations $[1,4,9,10]$. Such impacts will undoubtedly affect livelihoods through an increase in, and an exacerbation of, hydro meteorological hazards and changes in seasonal weather patterns affecting agricultural production. These impacts have been seen in Ethiopia particularly in the pastoral and agropastoral areas [11].

The Ethiopia Humanitarian Country Team (EHCT) has analyzed a wide range of data recommended by Ethiopia's National Meteorological Agency's analogue years of El Niño episodes of 1997 and 2002 to learn the lessons of the past and to inform future needs and implementation strategies. The major conclusion of this analysis is one of warning: without a robust response supported by the international community, there is a high probability of a significant food insecurity and nutrition disaster. (Ethiopia slow onset natural disaster, Sep 2015), this condition is more sever in the pastoral and agropastoral areas where the early warning system cannot be available easily and, the copping capacity is low $[11,12]$.

Somali region is one of the most food insecure regions in Ethiopia, with the large number of its population living at subsistence levels and dependent on livestock and crop production, which is highly vulnerable to any adverse condition and shocks in relation to climate change. Delayed seasonal rains are causing livestock loss and risk of food shortage in some parts of Ethiopia especially in Ethiopia Somali Region, particularly in Siti Zone (http://hornaffairs.com/en/2015/08/15/ethiopia-delayed-rains-causing-crisis-in-afar-somali-regions/; Zeray and Demie [12]. Siti zone is one of the zones in Ethiopia Somali region where camel production is the main source of livelihood; climate change has severely affected the camel production.

This needs urgent intervention based on the empirical data on the extent of the climate change impact on the camel production, and socioeconomic part of the agropastoral production system in turn. The climate change risk management and suitable coping strategies in relation to camel production to the specific study site are not yet made. Therefore, the current study is very crucial and current issue to assess the climate change risks, its management, and coping strategies; and intervention on coping strategies will be made in pilot woredas to enhance camel production and support the communities for food self-sufficiency.

\subsection{Objective}

To asses risk of Climate change on camel production

To identify local and innovative risk management options to reduce climate change risks on camel production

To recommend the best climate change risk management and coping strategies for sustainable camel production

\section{Material and Methodology}

The study was conducted at Siti Zone of Erer and Dembell Wereda of Somali regional state of Ethiopia in 201618 consequent years. The stations have an altitude ranges between 950-1350 meters above sea level. A low-lying flat semi-arid area to the north-central area of the Zone, with loose soils and covered by bush and woody grasses. These vast flat areas provide grazing areas for camel, cattle, goat, and sheep. The zone consists of undulating hilly parts interspersed with expansive plains. There are two rainy seasons in the Zone - Gu and karan, both of which are almost equally important. The Gu falls between late March and late May while the karan season is between late July to late September. In recent years, the karan has shown better reliability. Annual rainfall is between $500 \square 700 \mathrm{~mm}$. A lowland hill area neighboring these foothills that are used for irrigated farming and other agropastoral found in Meisso, Erer, Shinile and Dambal districts [11].

This project was implemented based on two phases: the first phase was an assessment of the Climate change risk on camel production, and the second phase will be an intervention phase to cope and manage the risk of Climate change on camel production based on first year finding.

Activity One: Assessment of Climate change risks, its management and coping strategies for camel production

The general approaches were used to assess the impact of past and current climate hazards in the agriculture sector (particularly in camel production) and local adaptation practices. The local adaptation practices followed by the community to minimize the impact of natural hazards like drought were documented by employing participatory rural appraisal methods. The most convenient method followed for documentation was focus group discussions in selected 8 kebeles. The time line analysis was followed where ever necessary to understand the past impacts of climate variability and adaptation practices. The seasonality diagramming was used to identify camel production, which is exposed to climate related hazards and possible adaptation practices at a specified time in a year.

The woredas were selected purposively based on the prone of climate change hazard, the potential for camel population, and socio-economic importance of camel production. The total sample size of 80 individuals (40 from each agropastoralist woreda) was involved to receive semi-structured questionnaire in this study. Sample households were selected using systematic random sampling procedure. The appropriate interval was determined by dividing the total population of the woredas ' $N$ ' by the desired number of samples ' $n=40$ '.

Secondary data sources that include the major effect of climate change on camel production, camel species affected, and available risk management and coping strategies were assessed. 
Primary data was collected using a semi-structured questionnaire and various Participatory Rural Appraisal (PRA) tools such as problem ranking and trend analysis through key informants and group discussion. A semistructured questionnaire was used to interview a total selected agropastoralists on different aspects of climate change effect on camel production, and risk management and coping strategies. With this regard, the available experience of the community was assessed and documented.

Participatory rural appraisal (PRA) tools were employed for the problem and/or preference prioritization through a total of four group discussions (one FGD which contains 10 individuals in each of the selected districts). Individual agropastoralists were interviewed. Such group discussions were carried out primarily with camel producers elder agropastoralists, socially respected individuals (Ugas), and DAs. The FGDs were carried through preparing the questioner checklist.

Collected quantitative data were analyzed using descriptive statistics such as percentage, frequency; mean difference. ANOVA was computed by using SPSS software (version16.0) with 95\% CI. Whereas, the qualitative data were analyzed using the pair-wise ranking method. Furthermore, it was narrated and explained logically based on the existing conditions and literature.

\section{Result and Discussion}

\subsection{Characteristics of the Households}

$72.5 \%$ of the respondents were males and the remaining $27.5 \%$ were females. $50 \%, 42.5 \%$ and $7.5 \%$ of the respondents were within the interval of 40-50, 30-40 and 20-30 age composition respectively. Majority of the respondents were with in age interval of 40-50. Similarly, most of the respondents were males that were $72.5 \%$.

Most of the respondents were illiterate (have not education) that was $70 \%$ of the total interviewed households. Only $30 \%$ of the respondents were educated that have been taken elementary school (grade 1-8).

\subsection{Production, Herd Composition and Management}

\subsubsection{Production Type}

As indicated in Figure 1 Majority of the interviewed households were depending on camel production as priority income source that was 76 respondents (48.7\%). According to the response given by the representative pastoralist and agropastoralists generate their income from camel and camel products. The economic importance of contraband remained insignificant.

Similarly as shown from Figure 1 the Crop production i.e $32.1 \%$, specifically horticultural crops like orange, mango, citrus and "khat" was the next income priority of the local community particularly for Bila and Arabe kebeles of Shinile and Dembel Woreda respectively. The two kebelles of the study areas have full potentials of irrigation that is why peoples of the local community were depended on crop production as a priority income. According to the response given by representative pastoralists and agropastoral in the study area the dominant crop grown in the study area was sorghum (25.8\%), maize (22.7\%), forage grass (19.6), orange (14.4\%), forage crop $(8.2 \%)$, wheat $(5.1 \%)$ and "khat" $(4.1 \%)$ respectively. Based on the survey result in the study area, Sorghum and Maize were accounted the largest proportion of production with the level of $25.8 \%$ and $22.7 \%$ respectively. In the area where there is crop production the farmers were used crop by product as a feed for small ruminant especially during the early growth stage of the crop.

Figure-1. Income Source of the Respondents of the Study Areas

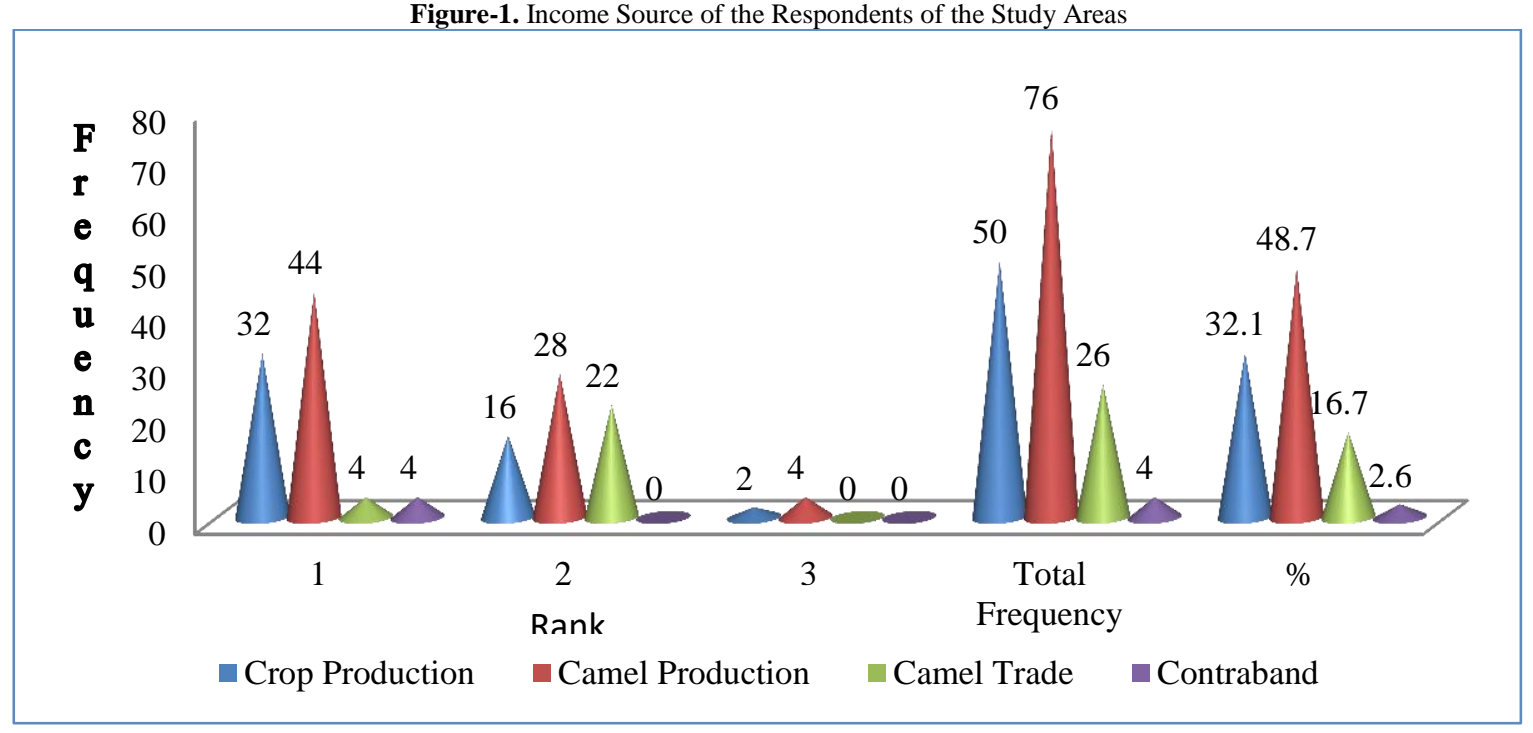

There are already over 1 billion (about $15 \%$ of the human population) people hungry and living in poverty, and $75 \%$ of them as well as other less poor but vulnerable people live in rural areas and depend on farming for their livelihoods, with the majority relying on small scale crop-livestock systems [13]. Peoples of the study areas produce a crop for different purposes such as for food, animal feed, and income generation. Food is the primary preference 
for the interviewed households that was around $40.8 \%$ of the total purpose of crop production. Income generation via the product of crops and animal feed were next to food that was $31.0 \%$ and $28.2 \%$ respectively.

\subsubsection{Animal Composition}

Table 1 shows the number of households who own livestock. As shown by the results, $28 \%$ of the households own both camel and goat equally, $27.3 \%$ own cattle only, $14.4 \%$ own the only sheep and $2.3 \%$ own only poultry.

Table-1. Type of Animals That Held by the Respondents

\begin{tabular}{|c|c|c|c|c|c|c|c|c|}
\hline \multirow[t]{2}{*}{$\mathbf{S} / \mathbf{N}$} & \multirow[t]{2}{*}{ Type of animals } & \multicolumn{5}{|c|}{ Rank Frequency } & \multirow[t]{2}{*}{ Total Frequency } & \multirow[t]{2}{*}{$\%$} \\
\hline & & 1 & 2 & 3 & 4 & 5 & & \\
\hline 1 & Cattle & 46 & 4 & 10 & 12 & 0 & 72 & 27.3 \\
\hline 2 & Camel & 8 & 54 & 12 & 0 & 0 & 74 & 28.0 \\
\hline 3 & Sheep & 2 & 4 & 10 & 22 & 0 & 38 & 14.4 \\
\hline 4 & Goat & 22 & 12 & 40 & 0 & 0 & 74 & 28.0 \\
\hline 5 & Poultry & 0 & 0 & 0 & 0 & 6 & 6 & 2.3 \\
\hline 6 & Others & 0 & 0 & 0 & 0 & 0 & 0 & 0 \\
\hline \multicolumn{2}{|c|}{ Total } & & & & & & 264 & \\
\hline
\end{tabular}

\subsubsection{Camel Herd Management}

This study provides evidence that camels remain the primary source of livelihoods even as pastoralists' transition to semi-sedentary urban lifestyle and milk is the key product. The relative importance attached to camels in both peri-urban and pastoral production systems as a livelihood source (Figure 2) is in agreement with previous reports [14-16]. The importance of camels may be attributed to their ability to survive the harsh environmental conditions [16-19]: while providing food by way of milk and meat. The camel plays varied roles in the pastoral and peri-urban production systems of Ethiopia Somali Region (Figure 2). Selected respondent of the study area responds that transportation was an important economic activity with $24.7 \%$, while both milk consumption and income generation were also the next important equally with $23.5 \%$ respectively. $22.3 \%$ meat and $6 \%$ drought/power were also the other importance of camel in the selected study areas of Somali region. This makes camel keeping a better livelihood source in the pastoral and agropastoral production system of Somali region. Therefore, strategies that enable increased productivity of camels in the pastoral and agropastoral system will be priority intervention for sustaining market-oriented camel production in the area. Increased camel production and productivity would contribute to the generation of income for the poor while sustaining the camel as a biodiversity genetic resource even under increasing sedentarisation processes of pastoral communities.

Figure-2. Purpose of Camel Production in the Study Area

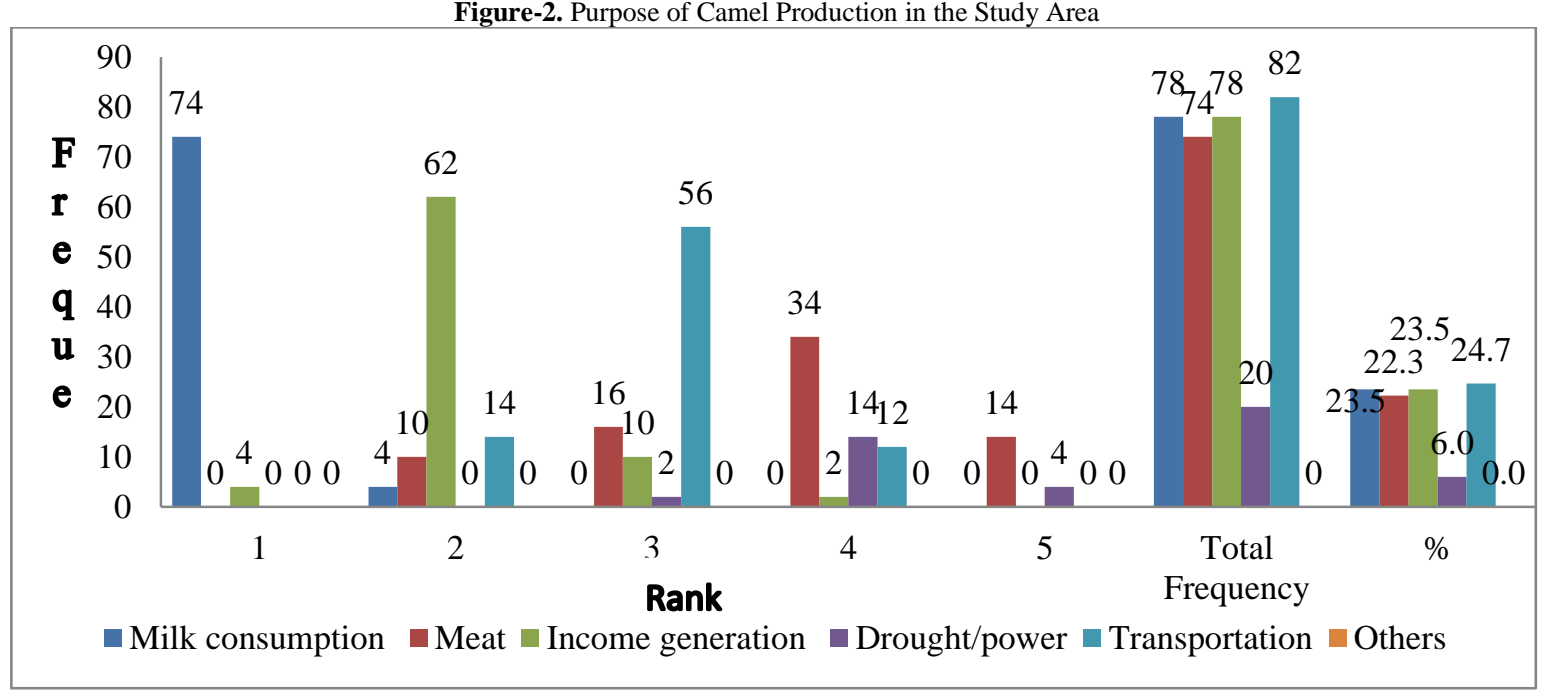

\subsubsection{Camel Feed Source and Their Couse for Shortage of Feed}

Animals adapt to fluctuations in forage quality by either selectively eating plants of high quality or by improving the digestion of poor forage through a longer retention time of ingesta particles in the fore stomach [20, 21]. However, the ability to feed selectively and to improve the digestion of the selected forage varies from one animal species to another [20].

Camels are selective feeders, having access to browse outside the range of other livestock. Camels consume a high protein diet if available, but if forced to feed on low quality fibrous diets they are able to recycle and use body urea efficiently $[22,23]$. Unlike other ruminants, camels have a higher capacity to utilize fibrous feed material by retaining it in the rumen for a longer period, allowing for better digestion [21, 23]. This mitigates the negative effects of high fibre content in camel diets. The camels ${ }^{\text {ee }}$ ability to select high quality feed is helped by the long and grasping upper lip and mobile tongue [23]. In addition, it has access to feed not available to other domestic species, even the goat, because of its height. Camel feed different type of plants like trees, shrubs, crop residue, supplementary feed 
and browsing, and grazing plants. According to respondents of the study areas around $39.2 \%$ of the household were trees and shrubs are the dominant type of feed for a camel. While 38.1\%, 19.6\%, and 3.1\% were for browsing and grazing in the range, crop residue, and supplementary feeding respectively (Figure 3 ).

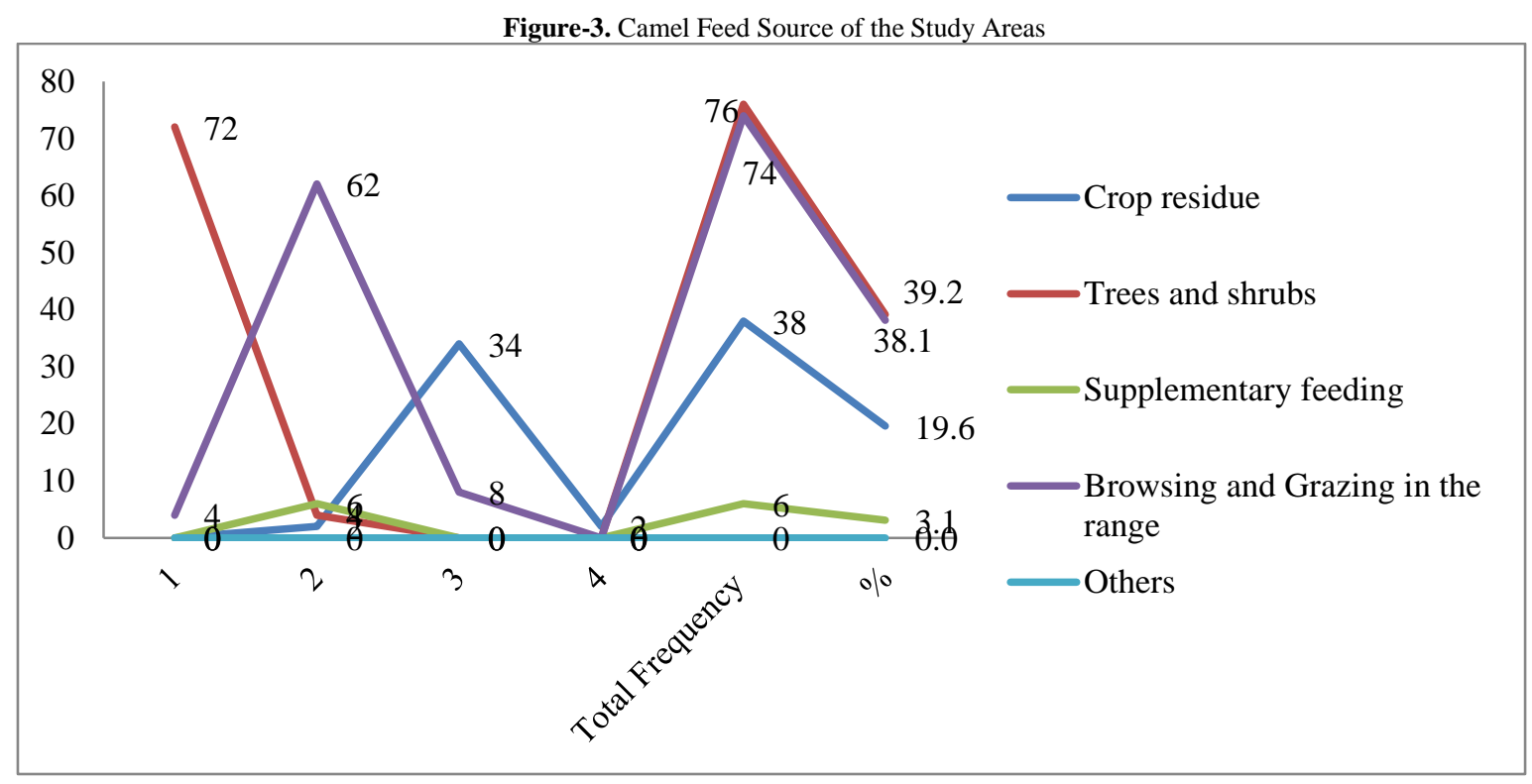

In most part of the study area $22.7 \%$ of the respondents were stated that drought is the most limiting factor for camel feed followed by Lack of supplementary feed sources (19.9\%), Lack of early warning system for climate change $(19.3 \%)$ and Lack of technology to conserve available feed (19.3\%) respectively (Table 2). However, the factors to be considered as a production constraint in the study area were include Drought, Lack of supplementary feed sources, Lack of early warning system for climate change, Lack of technology to conserve available feed, Lack of water sources and conservation skills, Lack of farmers motivation to adopt new technology, Animal health service and predator.

Table-2. Cause of Camel Feed Shortage

\begin{tabular}{|c|c|c|c|c|c|c|c|c|c|}
\hline \multirow[t]{2}{*}{$\mathbf{S} / \mathbf{N}$} & \multirow[t]{2}{*}{ Cause of shortage of feed } & \multicolumn{6}{|c|}{ Rank Frequency } & \multirow{2}{*}{$\begin{array}{l}\text { Total } \\
\text { Frequency }\end{array}$} & \multirow[t]{2}{*}{$\%$} \\
\hline & & 1 & 2 & 3 & 4 & 5 & 6 & & \\
\hline 1 & Drought & 80 & 0 & 0 & 0 & 0 & 0 & 80 & 22.7 \\
\hline 2 & Lack of technology to conserve available feed & 0 & 24 & 10 & 20 & 8 & 6 & 68 & 19.3 \\
\hline 3 & Lack of early warning system for climate change & 0 & 8 & 26 & 6 & 24 & 4 & 68 & 19.3 \\
\hline 4 & Lack of water sources and conservation skills & 0 & 26 & 4 & 8 & 4 & 2 & 44 & 12.5 \\
\hline 5 & Lack of farmers motivation to adopt new technology & 0 & 4 & 4 & 6 & 4 & 4 & 22 & 6.3 \\
\hline 6 & Lack of supplementary feed sources & 0 & 12 & 24 & 26 & 4 & 4 & 70 & 19.9 \\
\hline 7 & Others & 0 & 0 & 0 & 0 & 0 & 0 & 0 & 0.0 \\
\hline \multicolumn{2}{|c|}{ Total } & & & & & & & 352 & \\
\hline
\end{tabular}

\subsubsection{Water Sources}

Although Water is an essential part of an animal's diet, the camel can survive a long period without drinking, and then replenish the loss in very short time [24, 25]. In autumn, when grazing on acacia, the camels requires $41 / 2$ liters of water per day, this increase to 13 liters in spring and reaches to 30 liters a day when grazing on salty pastures. Even on dry food, straw, and concentrated feed, the camel is unaffected by lack of water for up to ten days or more [25]. The mechanisms that enable the camel to go a long period without water are those which allow for a low rate water loss and high tolerance to dehydration. Camels are using a different source of water for drinking among them Stream, Pond, Dam, Birka and Wells. The interviewed household of the study area was responding that $46.2 \%$ of water source for camel were from Pond. While Stream and Dam were the next sources of water with $38.5 \%$ and $15.4 \%$ respectively (Table 3 ).

Table-3. Source of Water for a Camel

\begin{tabular}{|c|c|c|c|c|c|c|c|}
\hline \multirow{2}{*}{$\mathbf{S} / \mathbf{N}$} & \multirow{2}{*}{ Source of water } & \multicolumn{4}{|c|}{ Rank Frequency } & \multirow{2}{*}{ Total Frequency } & \multirow{2}{*}{$\%$} \\
\hline & & 1 & 2 & 3 & 4 & & \\
\hline 1 & Well & 0 & 0 & 0 & 0 & 0 & 0 \\
\hline 2 & Birka & 0 & 0 & 0 & 0 & 0 & 0 \\
\hline 3 & Dam & 0 & 20 & 0 & 0 & 20 & 15.4 \\
\hline 4 & Pond & 28 & 32 & 0 & 0 & 60 & 46.2 \\
\hline 5 & Stream & 50 & 0 & 0 & 0 & 50 & 38.5 \\
\hline \multicolumn{2}{|l|}{ Total } & & & & & 130 & \\
\hline
\end{tabular}




\subsubsection{Climate Change}

Climate change affects ecosystems and production systems at different scales. It is also expected to affect agricultural and livestock production, water balances, input supplies and other components of agricultural systems [26]. Climate change can retard development efforts and achievements by years [27]. The devastating effects of global climate change are increasing, and most damages are predicted to occur in developing countries. This is because of their over reliance rain fed agricultural production and their low adaptive capacity [28]. Majority of the rural population in the developing countries depends on crop and livestock production for their livelihoods [29]. Livestock took a lion's share in semi-arid areas. However, the livestock sector is highly vulnerable to climate change. Many climate change predictions suggest that the African livestock sector will be negatively affected by 2020 unless the current negative trend is reversed through adaption and mitigation mechanisms [30].

\subsubsection{Impact of Climate Change on Camel Production}

Climate change is affecting rains, an the increase in frequency of drought and rise in temperatures, threatening the availability of fresh water for agricultural production and other uses [31]. IPCC [8] concluded that climate change may severely compromise food production and food security in many African countries. This is mainly because farming in Africa is highly dependent on rain-fed agriculture [32] either through crop production or livestock rearing.

In most part of the study area, $19.6 \%$ of the respondents were stated that Camel disease incidence, Feed shortage and Water shortage were the most importance effect of climate change factor for camel production followed by Abortion (17.2\%). However, the factors to be considered as a production constraint in the study area included Camel Market failure (8.8\%), Sudden death of Camel (7.8\%) and Heat stress (7.4\%) respectively (Table 4).

Table-2. Effects of Climate Change on Camel Production

\begin{tabular}{|c|c|c|c|c|c|c|c|c|}
\hline \multirow[t]{2}{*}{ Rank } & \multicolumn{8}{|c|}{ Rank Frequency of Climate Change Risk } \\
\hline & $\begin{array}{l}\text { Camel } \\
\text { Disease } \\
\text { Incidence }\end{array}$ & $\begin{array}{l}\text { Camel } \\
\text { Market } \\
\text { Failure }\end{array}$ & $\begin{array}{l}\text { Feed } \\
\text { Shortage }\end{array}$ & $\begin{array}{l}\text { Water } \\
\text { Shortage }\end{array}$ & $\begin{array}{l}\text { Heat } \\
\text { Stress }\end{array}$ & Abortion & $\begin{array}{l}\text { The } \\
\text { sudden } \\
\text { Death of } \\
\text { Camel }\end{array}$ & Other \\
\hline$\overline{1}$ & 18 & 2 & 28 & 32 & 0 & 0 & & \\
\hline 2 & 32 & 6 & 38 & 2 & 0 & 0 & 2 & \\
\hline 3 & 28 & 16 & 8 & 6 & 0 & 20 & 2 & \\
\hline 4 & 2 & 10 & 4 & 22 & 2 & 30 & 14 & \\
\hline 5 & 0 & 0 & 2 & 4 & 6 & 12 & 8 & \\
\hline 6 & 0 & 2 & 0 & 14 & 4 & 6 & 4 & \\
\hline 7 & 0 & 0 & 0 & 0 & 18 & 2 & 2 & \\
\hline $\begin{array}{l}\text { Total } \\
\text { Frequency }\end{array}$ & 80 & 36 & 80 & 80 & 30 & 70 & 32 & 0 \\
\hline$\%$ & 19.6 & 8.8 & 19.6 & 19.6 & 7.4 & 17.2 & 7.8 & 0.0 \\
\hline
\end{tabular}

\subsubsection{Indigenous Knowledge (Indicators) of Climate Change}

Climate data for more than five decades indicates that the amount of rainfall has been constant on a national average [33, 34]. In Somali Region, rainfall data from 1957-2002 show an increase of rainfall in the Gu season and consistency in the Deyr rainfall [35]. Maybe the inconsistency of the climate data and community perceptions can be attributed to a combination of factors. Firstly, the climate data stations are too small to reflect the reality under the spatial distribution of different climatic conditions. Secondly, averages are not good indicators of rainfall distribution in space and time.

As shown in Figure 4, most of the agropastoralist and pastoralist communities in the four different locations of the study areas feel that Dry Climate $(32.5 \%)$ was the dominant indicator of climate change followed by Disease Incidence (22.5\%) and Change of Wind (speed and direction) (22.5\%). Season variation, Sun Over Head and Feed Shortage were also the other indicators. 


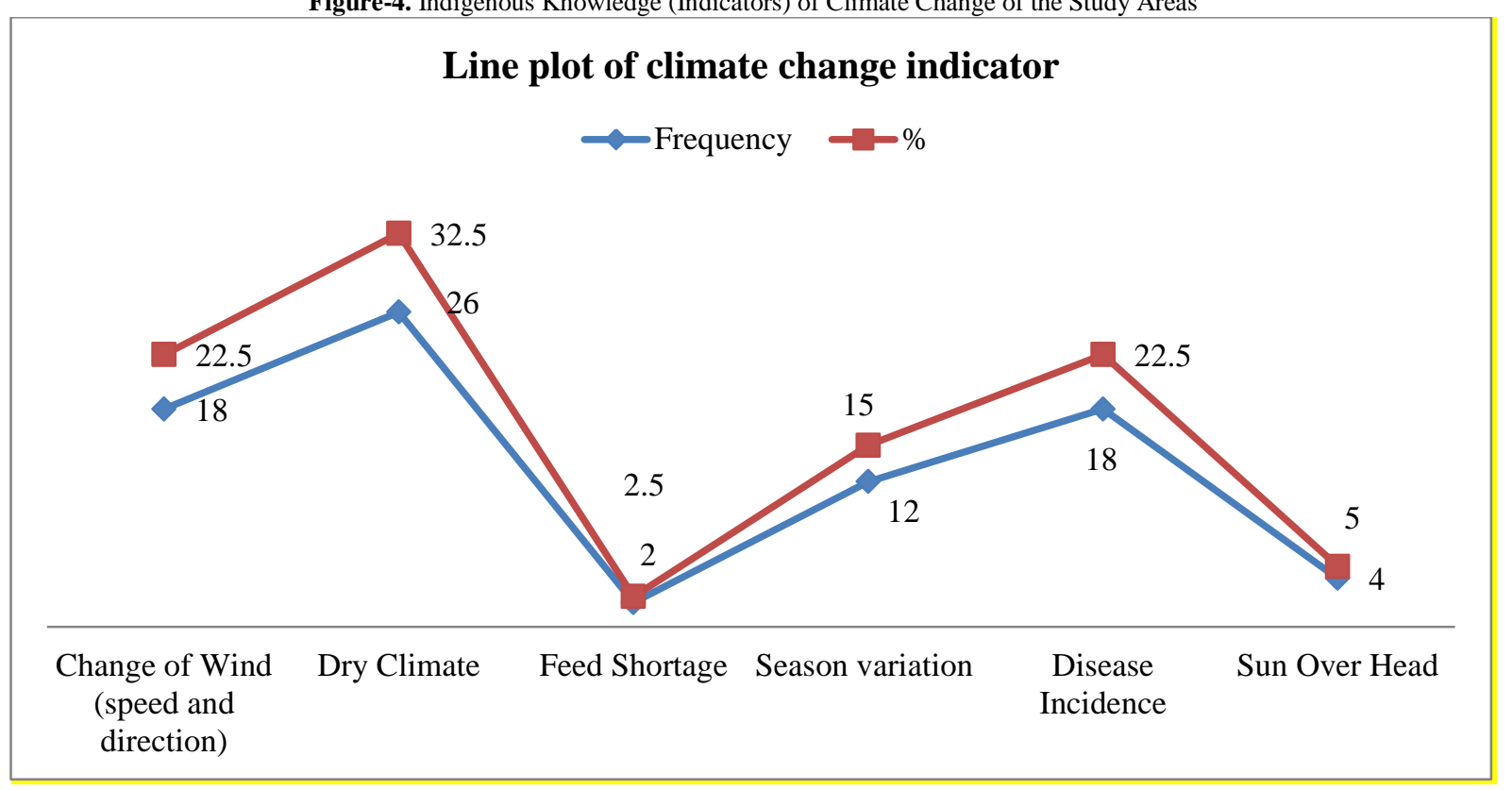

\subsubsection{Climate Change Risk Management and Coping Strategies for Sustainable Camel Production}

Changing environments may provide suitable conditions for the expansion of pastoralism, as the flexibility and mobility afforded by pastoralism may increasingly provide a means of providing security where other sedentary models fail. Pastoralists are the most capable to adapt to climate change, since pastoral livelihoods are shaped to deal with scarce and variable natural resources and to tackle difficult and uncertain agroecological conditions, and climate change could conceivably lead to the extension of territories where pastoralism could show comparative advantages [5].

Many possible Risk Management and Coping Strategies options do exist in the local community, such as Temporary camel relocation to other zones, Planting drought tolerant browse trees, establishing irrigated forage crops, Conserving rain water, Establishing water points, Developing animal health care centers, Selling camels and Restocking. According to the response of the interviewed agropastoralists $24.8 \%$ of the respondent stated that Temporary camel relocation to other zones was the major one for climate Risk Management and Coping Strategies followed by Restocking (16.8\%), Planting drought tolerant browse trees (16.1\%), Conserving rain water (13.7\%), Selling camels (12.4\%), Establishing irrigated forage crops (10.6\%), Developing animal health care centers (3.7\%) and Establishing water points (1.9\%) respectively (Figure 5).

All these options aim at increasing the Risk Management and Coping Strategies capacity of poor livestock keepers and agropastors. Given this range of options, there is a real need for methods and tools to assess what may be appropriate and where? This includes the collation of toolboxes of climate risk Management options and the identification of the domains where these may be relevant, at broad scales through the use of spatial analysis, and at more localized scales through more participatory, community-based approaches.

Most national and international climate change policy documents hardly recognize traditional and indigenous coping strategies. This needs to be rectified. Indeed, traditional and indigenous peoples "may have valuable lessons to offer about successful and unsuccessful adaptations which could be vital in the context of climate change". Because of their long dependence on nature they have developed strategies to cope with climate change and extreme natural events which still have as much relevance today as they did centuries ago.

Figure-5. Climate Change Risk Management and Coping Strategies for Camel Production of the Study Areas

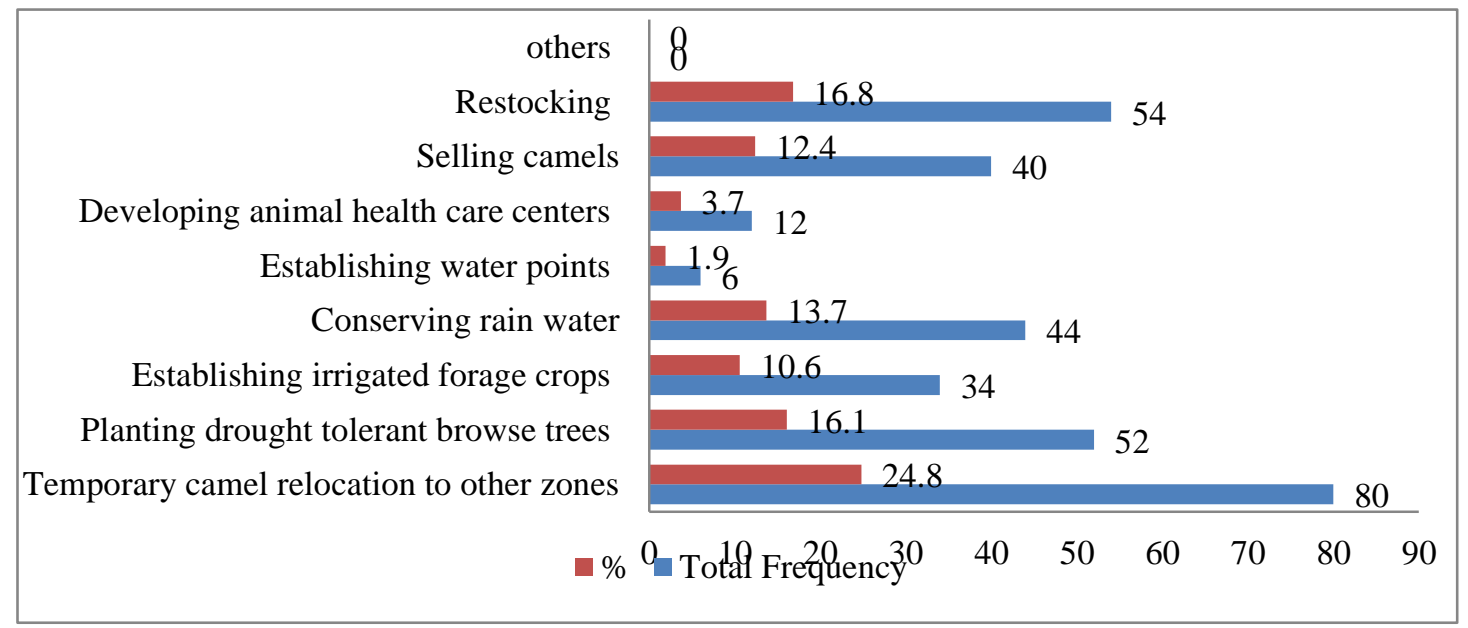




\subsubsection{Suggested Activities to Avoid Climate Change and Draught Impact on Camel Production}

The respondents were asked to indicate what they thought could be done to help them cope with and manage the risks of climate changes. In their response, they mentioned a number of suggestions which include establishment of Pond, Establish Water points, Feed Conservation techniques, Feed Supplementation, Animal Health center, introducing new Technology, Market Access, Migration to other area, Planting Forage Crop, Planting Drought Tolerant fodder Trees, Protecting Area from free grazing and Salt For Camel (Figure 6). 21.9\% of the respondent suggested that Feed Supplementation was the most important to tackle with the climate change followed by Planting Forage Crops (17.2\%), Migration to other area (14.1\%), Establish Water points (12.5\%), Market Access (12.5\%), Planting Drought Tolerant fodder Trees, Protecting Area from free grazing (3.1\%), Establish Pond (1.6\%), Feed Conservation techniques (1.6\%), Animal Health center (1.6\%), Introducing new Technology (1.6\%) and Salt For Camel $(1.6 \%)$.

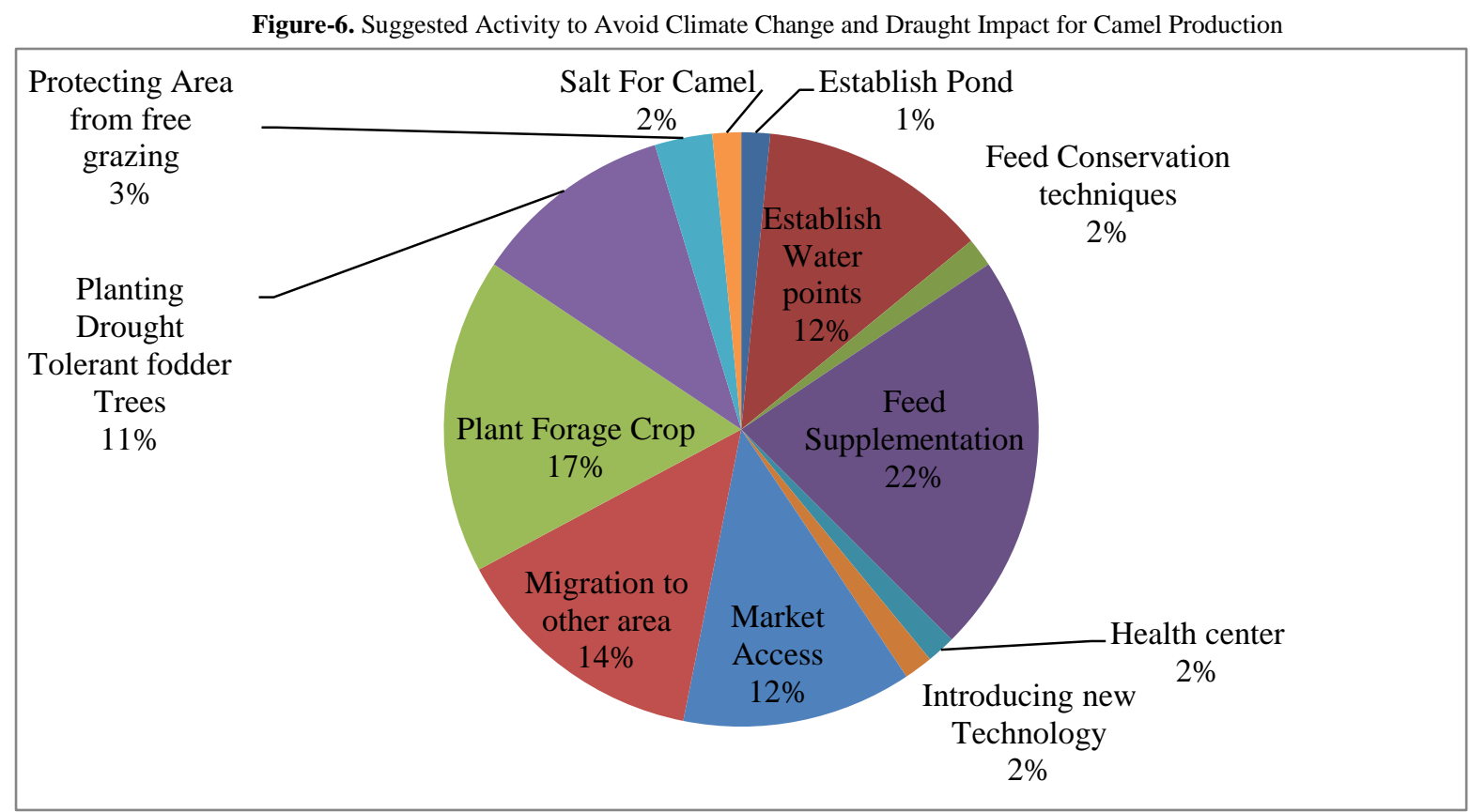

\section{Conclusion and Recommendation}

Somali region is one of the most food insecure regions in Ethiopia, with the large number of its population living at subsistence levels and dependent on livestock and crop production, which is highly vulnerable to any adverse condition and shocks in relation to climate change [11].

Camel is still the main source of income of rural populations in the Somali region. It needs urgent intervention based on the empirical data on the extent of the climate change impact on the camel production, and socioeconomic part of the agropastoral production system in turn. Considering those factors, the project was focusing on the main objective to identify Climate change risk management and coping strategies for sustainable camel production in the case of the Somali region, Ethiopia. Primary and secondary data were collected.

Camel production is construed to have reduced by climate change owing to other factors like Camel disease incidence, Feed shortage, and Water shortage equally with 19.6\%. On the other hand, Abortion, Camel Market failure, Sudden death of Camel and Heat stress were the other factors of climate change in the study area that have factors on camel production with $17.2 \%, 8.8 \%, 7.8 \%$, and $7.4 \%$ respectively. Those all consequence of climate change affected camel production negatively due to its impact on grazing and fodder quantity and quality.

The households were found to have devised some risk management and coping strategies, the main ones were Temporary camel relocation to other zones $(24.8 \%)$, Restocking (16.8\%), Planting drought tolerant browses trees $(16.1 \%)$, Conserving rain water $(13.7 \%)$, Selling camels $(12.4 \%)$, Establishing irrigated forage crops $(10.6 \%)$, Developing animal health care centers $(3.7 \%)$ and Establishing water points $(1.9 \%)$ respectively. However, the sustainability of those strategies especially the six top ones mostly used is in huge doubt. Similarly, the community is oblivious of the impact their actions had on the environment.

It was also noted that the local communities were suggested to Establish Pond, Establish Water points, Feed Conservation techniques, Feed Supplementation, Animal Health center, introducing new Technology, Market Access, Migration to another area, Planting Forage Crops, Planting Drought Tolerant fodder Trees, Protecting Area from free grazing and Salt For Camels.

This study was not exhaustive on its own. It was not possible to conduct a more extensive study that can be extrapolated due to time and financial constraints. Therefore, it is suggested to conduct a more extensive research. Moreover, the study also recommends provision of water sources, planting drought tolerant browse trees, Feed Supplementation, and Planting Forage Crop to the study areas. The study further recommends that Awareness creation among pastoralists and agropastoral regarding on the risk management and coping strategies for sustainable 
camel production, vigorous dissemination of the technologies information and follow-up to ensure utilization and/or application are strongly recommended.

\section{Acknowledgment}

We would like to express our first and foremost gratitude to Ethiopian Institute of Agricultural Research (EIAR) for its financial support. Special gratitude goes to the interviews and focuses groups for their hospitality, for generosity in providing crucial information. Our gratitude goes to Jigjiga University for providing the necessary facilities and support during this report preparation and the whole research time.

\section{Reference}

[1] Shea, E., 2001. Pacific island regional assessment of the consequences of climate change and variability (The Pacific Assessment). Honolulu: East-West Center.

[2] IPCC, 2007. "(Intergovernmental panel on climate change) Climate Change 2007, Impacts, Adaptation and vulnerability, Summary for policy makers." Available: Http://www.ipcc.Cg/SPM13apr07.pdf

[3] GLCA, 2009. "Facilitating an international agreement on climate change, Adaptation to climate change, A proposal of Global leadership for climate action."

[4] Shea, E., 2003. Living with a climate in transition, Pacific communities plan for today and tomorrow. Honolulu, East-West Center.

[5] MacOpiyo, L., Angerer, J., Dyke, P., and Kaitho, R., 2008. "Experiences on mitigation or adaptation needs in Ethiopia and East African rangelands." In Proceedings Livestock and Global Climate Change International Conference (P. Rowlinson, M. Steele and A. Nefzaoui, eds.), 17-20 May, 2008, Hammamet, Tunisia. pp. 64-67.

[6] ISDR, 2008. "(International strategy for disaster reduction), Climate change and disaster risk reduction, Brief note 01, Geneva September 2008."

[7] IFRC, 2009. "(International federation of red cross and red crescent societies), RC/RCCCPC (Red Cross / Red crescent climate centre and provention consortium in collaboration with Ken Westgate, independent consultant), Climate change adaptation strategies for local impact. Key Messages for UNFCCC Negotiators. Technical Paper for the IASC Task force on climate change."

[8] IPCC, 2007. Africa, climate change 2007, impacts, adaptation and vulnerability, The contribution of working group II to the Fourth assessment report of the intergovernmental panel on climate change. Cambridge UK: Cambridge University Press. pp. 433-467.

[9] Lewis, J., 1999. Development in disaster-prone places, studies of vulnerability. ITDG Publishing.

[10] UNFCCC (United Nations Framework Convention on Climate Change), 2005. Climate change, small island developing states. Bonn, UNFCCC.

[11] SCUK and DPPA, 2008. Livelihoods and vulnerabilities - an understanding of livelihoods in Somali Regional State, Ethiopia, SCUK and Disaster Prevention and Preparedness Agency. Addis Ababa, Ethiopia.

[12] Zeray, N. and Demie, A., 2015. "Climate Change Impact, Vulnerability and Adaptation Strategy in Ethiopia, A Review."

[13] Food and Agricultural Organisation (FAO), 2014. "Climate change, Climate change impacts, adaptation and vulnerability, IPCC WG II Forht Assessment Report."

[14] Yagil, R., 1986. "The supreme animal for hot, dry and arid desert lands -The dromedary." World Animal Review, vol. 57, pp. 2-10.

[15] Stiles, D., 1987. "Camel vs cattle pastoralism: stopping desert spread." Desertification Control Bulletin, vol. 14, pp. 15-21.

[16] Guliye, A. Y., Noor, I. M., Bebe, B. O., and Koskey, I. S., 2007. "Role of camels (Camelus dromedarius) in the traditional lifestyle of Somali pastoralists in northern Kenya." Outlook on Agriculture, vol. 36, pp. 2934. Available: http://hornaffairs.com/en/2015/08/15/ethiopia-delayed-rains-causing-crisis-in-afar-somaliregions/ http://reliefweb.int/disaster/dr-2015-000109-eth

[17] Yagil, R., 1985. The desert camel, Comparative physiological adaptation, Comparative animal nutrition vol. 5. Basel: Karger.

[18] Rutagwenda, T., Kaske, M., Engelhardt, W. V., Lechner-Doll, M., Schultka, W., and Schwartz, H. J., 1989. "Adaptation strategies of camels on a thornbush savannah pasture: comparison with other domestic animals." Options Méditerranéennes-Série Séminaires, vol. 2, pp. 69-73.

[19] Schwartz, H. J., 1992a. "Productive performance and productivity of dromedaries (Camelus dromedarius)." Journal of Animal Research and Development, vol. 35, pp. 86-98.

[20] Rutagwenda, T., Lechner-Doll, M., Schwartz, H. J., Schultka, W., and von Engelhardt, W., 1990. "Dietary preference and degradability of forage on a semiarid thornbush savannah by indigenous ruminants, camels and donkeys." Animal Feed Science and Technology, vol. 31, pp. 179-192.

[21] Lechner-Doll, M., Rutagwenda, T., Schwartz, H. J., Schultka, W., and Von Engelhardt, W., 1990. "Seasonal changes of ingesta mean retention time and fore stomach fluid volume in indigenous camels, cattle, sheep and goats grazing a thorn bush savannah pasture in Kenya." Journal of Agriculture Science Cambridge, vol. 115 , pp. 409-420. 
[22] Field, C. R., 1995. The camel and its place in Pastoral life - a desert dairy. In, Evans, J. O. Simpkin, S.P. and Atkins, D. J. 1995. Camel keeping in Kenya, Range Management Handbook of Kenya, Vol. III, 8, Ministry of Agriculture, Republic of vol. 3. Kenya: Livestock Development and Marketing.

[23] Wilson, R. T., 1998. Camels, The tropical agriculturalist, CTA. Netherlands.

[24] Schmidt-Nielsen, K., 1964. Desret animals, Adaptation and environment. Oxford: Oxford University Press. p. 277.

[25] Yagil, R., Sod-Moriah, U. A., and Meyerstein, N., 1974. "Dehaydration and camel blood, the life span of the camel erythrocyte." J. Phsiol., vol. 226, pp. 298-301.

[26] Aydinalp, C. and Cresser, M. S., 2008. "The effects of global climate change on agriculture." AmericanEurasian Journal of Agriculture and Environmental Sciences, vol. 3, pp. 672-676.

[27] Adem, A. and Bewket, W., 2011. A climate change country assessment report for Ethiopia submitted to Forum for Environment (On behalf of ECSNCC). Addis Abeba, Ethiopia: Epsilon International R and D.

[28] Bruckner, M., 2012. "Climate change vulnerability and the identification of LDCs, The united nations development policy and analysis division department of economic and social, Affairs."

[29] Musemwa, L., Mushunje, A., Chimonyo, M., Fraser, G., Mapiye, C., and Muchenje, V., 2008. "Nguni cattle marketing constriants and opportunities in the communal areas of South Africa, Review." African Journal of Agricultural Research, vol. 3, pp. 239-245.

[30] Calvosa, C., Chuluunbaatar, D., and Fara, K., 2009. "Livestock and climate change, livestock thematic papers tools for project design."

[31] Kotir, J. H., 2010. "Climate change and variability in Sub-Saharan Africa, A review of current and future trends and impacts on agriculture and food security Springer." Journal of Environment and Sustainable Development,

[32] GECHS, 2008. "Climate change in eastern and southern Africa, Impacts, Vulnerability and adaptation accessed from." Available: www.gechs.org/publications/reports/

[33] Abebe, T., 2008. "National adaptation program of action (NAPA) preparation process in Ethiopia. In, Green Forum (ed.) Climate change - a burning issue for Ethiopia." In Proceedings of the 2nd Green Forum Conference held in Addis Ababa, 31 October-2 November 2007 (Addis Ababa, Green Forum). pp. 70-110.

[34] Daniel, K., 2008. "Impacts of climate change on Ethiopia, a review of the literature. In, Green Forum (ed.)." In Climate change - a burning issue for Ethiopia, proceedings of the 2nd Green Forum Conference held in Addis Ababa, 31 October-2 November 2007 (Addis Ababa, Green Forum). pp. 9-35.

[35] Devereux, S., 2006. Vulnerable livelihoods in Somali Region, Ethiopia, IDS Research Report 57. Brighton: Institute of Development Studies. 